\title{
PENDIDIKAN ANAK DALAM KELUARGA SINGLE PARENT PEREMPUAN
}

\author{
CHILDREN'S EDUCATION IN SINGLE-PARENT WOMEN
}

\author{
Dewi Sulistyaningsih \\ Filsafat dan Sosiologi Pendidikan, Kebijakan Pendidikan FIP UNY \\ dewisulis0801@gmail.com
}

\begin{abstract}
Abstrak
Penelitian ini bertujuan untuk mendiskripsikan 1) Pendidikan Anak dalam Keluarga Single Parent Perempuan, 2) Problem-problem yang dialami ibu single parent, 3) Solusi yang dilakukan oleh ibu single parent dalam mengatasi problem pendidikan anaknya. Penelitian ini menggunakan pendekatan kualitatif dengan jenis studi kasus. Penelitian dilaksanakan di Desa Karangrejek Wonosari Gunungkidul. Subyek penelitian adalah perempuan yang telah bercerai atau ditinggal suami meninggal, perempuan bekerja mencari nafkah dan berstatus single parent, perempuan single parent yang masih menyekolahkan anaknya. Pengumpulan data dilaksanakan dengan wawancara mendalam dan studi dokumentasi. Analisis data menggunakan model interaktif. Uji keabsahan data menggunakan triangulasi teknik dan sumber. Hasil penelitian menunjukkan sebagai berikut:1) Pendidikan anak dalam keluarga single parent perempuan dalam mendidik anak di dalam keluarga memiliki beberapa cara yaitu memberikan nasihat, memberikan teladan, memberikan pengawasan, serta memberikan hukuman. 2) Problem yang dialami ibu single parent dalam pendidikan anaknya berasal dari diri anak sendiri misalnya malas belajar, anak suka membantah kalau dikasih tahu, kondisi ekonomi yang relatif lemah berdampak pada terbatasnya biaya pendidikan anak yang terkadang harus berhutang, dan kesulitan dalam kebutuhan sehari-hari. 3) Solusi yang dilakukan oleh ibu single paent dalam mengatasi problem pendidikan anaknya yaitu, memberikan nasihat, memberikan motivasi, mengontrol kegiatan anak, dan single parent banting tulang setiap hari untuk memenuhi kebutuhan sehari-hari, serta mencari bantuan dari pihak lain yaitu dari bapak dan bantuan dari saudaranya.
\end{abstract}

Kata Kunci: Pendidikan, single parent perempuan

\begin{abstract}
This research aims to describe 1) Children's education in Single-Parent women's Families, 2) The problems of single-parent mothers, and 3) a single-parent solution that is done in resolving the child's educational problems. This study used a qualitative approach with this type of case study. The study was conducted in Karangrejek village in Gunungkidul. The subject of the study is a woman who has divorced or left her husband dead, women working to make a living and the status of single parent, female single parent who still subsisted her child. Data collection is implemented with in-depth interviews and documentation studies. Analyze data using interactive models. Test the legality of data using triangulation techniques and sources. The results showed as follows: 1) The education of children in single parent female families in educating children in the family has several ways, namely giving advice, setting an example, providing supervision, and providing punishment. 2) Problems experienced by single parent mothers in their children's education come from their own children, for example, lazy to learn, children like to argue if they are told, relatively weak economic conditions have an impact on the limited cost of children's education, which sometimes must be in debt, and difficulties in needs daily. 3) The solution carried out by single paent mothers in overcoming their children's education problems is, giving advice, providing motivation, controlling children's activities, and single parent slamming bones every day to meet their daily needs, as well as seeking help from other parties namely from the father and help from his brother.
\end{abstract}

Keywords: education, single-parent women 


\section{PENDAHULUAN}

Anak merupakan manusia yang masih kecil. Anak membutuhkan peran orang dewasa untuk membantu mengembangkan kemampuannya. Anak perlu mendapatkan kesempatan yang seluas-luasnya untuk tumbuh dan berkembang secara optimal, baik fisik, mental maupun sosial, dan berakhlak mulia. Salah satunya perlu dilakukan upaya perlindungan dan juga anak memiliki hakhak dasar yang harus di penuhi.

Pemenuhan atau hak-hak anak di Indonesia diatur dalam Undang-Undang No. 35 Tahun 2014 yang menyebutkan bahwa hak anak adalah bagian dari Hak Asasi Manusia yang dijamin, dilindungi, dan dipenuhi oleh orang tua, keluarga, masyarakat, negara pemerintah, dan pemerintah daerah. Salah satunya hak anak yang harus dipenuhi adalah hak untuk mendapatkan pendidikan yang layak seperti yang tercantum dalam Undang-Undang No. 20 Tahun 2003 pasal 5 yang menyatakan bahwa setiap warga negara memiliki hak yang sama untuk memperoleh pendidikan yang bermutu.

Pendidikan saat ini sangat berperan penting dalam suatu kemajuan bangsa, bahkan pendidikan meningkatkan kualitas hidup dan derajat kesejahteraan masyarakat. Pendidikan merupakan usaha sadar dan terencana untuk mewujudkan suasana belajar dan proses pembelajaran agar peserta didik secara aktif mengembangkan potensi dirinya untuk memiliki kekuatan spiritual keagamaan, pengendalian diri, kepribadian, kecerdasan, akhlak mulia, serta ketrampilan yang diperlukan dirinya, masyarakat, bangsa dan negara (Undang-undang No.20 Tahun 2003).

Pendidikan anak tidak lepas salah satunya dari pembiayaan pendidikan yang meliputi biaya investasi, biaya operasi, dan biaya personal. Biaya personal sebagaimana dimaksud biaya pendidikan yang harus dikeluarkan oleh peserta didik untuk bisa mengikuti proses pembelajaran secara teratur dan berkelanjutan (Permen No.69 Tahun 2009). Pendidikan anak menjadi kewajiban umumnya kedua orang tua salah satunya memenuhi kebutuhan hak anak yaitu menempuh pendidikan. Pada realitanya banyak orang tua tunggal terutama perempuan yang menghidupi keluarganya.

Keluarga merupakan suatu kelompok yang terdiri dari Ibu, Bapak, dan berserta anak-anaknya seisi rumah (KBBI : 2018). Dalam kehidupan keluarga, suami istri umumnya memegang peranan dalam pembinaan kesejahteraan bersama. Kewajiban untuk memperoleh penghasilan 
keluarga secara terutama dibebankan kepada suami sebagai kepala keluarga, sedangkan peran istri dalam hal ini sebagai penambah penghasilan keluarga. Penghasilan keluarga umumnya digunakan untuk memenuhi kebutuhan makan, tempat tinggal, dan juga salah satunya untuk biaya pendidikan anak.

Dalam realita masyarakat cukup banyak keluarga single parent terutama orang tua tunggal akibat perceraian. Undang-Undang Perkawinan No 1 Tahun 1974, disebutkan tiga sebab yang dapat mengakibatkan terputusnya suatu perkawinan yaitu kematian, penceraian, dan atas keputusan pengadilan. Pada berbagai kasus di Indonesia, bentuk keluarga dengan orang tua tunggal yang sering dijumpai. Lopata (Ollenburger Jane 1996 : 248), menyatakan perbedaan utama yang terjadi pada seorang wanita ketika suaminya meninggal, tampaknya adalah apakah ia sendiri harus mengatur kembali sistemsistem dukungan dan gaya hidupnya, sebagaimana ciri khas wanita modern di pusat-pusat perkotaan yang lebih berkembang, atau apakah integrasi sosialnya disediakan oleh orang-orang lain. Perempuan sebagai orang tua tunggal memiliki posisi yang penting dalam keluarga. Perubahan peran dari istri menjadi janda dan berperan sebagai ibu sekaligus ayah yang merawat dan mendidik anak- anaknya serta mencari nafkah keluarga.

Penyandang duda maupun janda baru di Kabupaten Gunung Kidul terus mengalami peningkatan setiap harinya. Pengadilan agama rata-rata dalam sehari memutuskan 4 perkara. Pada tahun 2015 perceraian yang masuk ke Pengadilan Agama sejumlah 1.452 perkara, terdapat cerai talak sebanyak 445 perkara dan cerai gugat 1.007 perkara. Selanjutnya tahun 2016 cerai talak menjadi 397 perkara, cerai gugat sebanyak 1.142 perkara dan jumlah yang masuk ke Pengadilan Agama sebanyak 1.539. Ketua pengadilan agama Gunung Kidul melalui Panitera Hukum, A. Fatkhurohman mengatakan, mendekati akhir tahun 2017 ini tercatat ada 1.548 perkaran perceraian yang masuk ke Pengadilan Agama. Dari jumlah tersebut sebanyak 1.169 perkara telah berhasil diputus oleh hakim (gunungkidul.sorot.co). Tahun 2018 perkara penceraian yang masuk ke Pengadilan Agama sebanyak 1.920 perkara.

Tidak mudah bagi perempuan single parent untuk menjalani dua peran sekaligus, di satu sisi harus bertanggungjawab dalam mengurus dan membina keluarga secara baik seperti yang diungkapkan oleh Tatik Rahayu (2014), dalam penelitiannya bahwa setelah menjadi single parent berperan ganda dalam kehidupan sehari-hari, selain menjadi ibu yang tugasnya mendidik dan 
membimbing anak, seorang single parent juga harus bisa mencari nafkah untuk kebutuhan sehari-hari. Perempuan yang memiliki peran ganda terkadang dapat menganggu kegiatan dan konsentrasi dalam bekerja karena terbagi dengan perannya sebagai ibu rumah tangga. Perempuan dengan peran ganda sering mengalami konflik dalam dirinya karena adanya pertentangan antara tanggungjawab yang dimilikinya sebagai ibu rumah tangga serta tugasnya dalam menghidupi keluarga, seperti halnya yang diungkapkan oleh Ika Rahmawati (2015) dalam penelitiannya, bahwa status orang tua tunggal dipandang sebelah mata oleh masyarakat, stigma negatif yang terdapat di masyarakat seperti anak dari keluarga tersebut sulit diatur, sering bermasalah, kurang harmonis. Peran perempuan single parent memberikan konsekuensi yang berat, ibu harus bertanggungjawab kepada keluarga terutama anak. Seorang anak membutuhkan seseorang yang mampu menjamin kehidupannya salah satunya dari segi kebutuhan ekonomi anak, lantaran tidak hadirnya salah satu orang tua kondisi ekonominya lemah (Rizqi: 2013).

Oleh sebab itu penelitian ini bertujuan untuk mendapatkan gambaran bagaimana langkah seseorang ibu yang single parent dapat memberi pendidikan yang layak pada anaknya.

\section{METODE PENELITIAN}

\section{Jenis Penelitian}

Penelitian ini menggunakan pendekatan penelitian kualitatif deskriptif.

\section{Waktu dan Tempat Penelitian}

Penelitian ini dilaksanakan pada bulan April-Juli 2019 di Desa Karangrejek Wonosari Gunungkidul.

\section{Subjek Penelitian}

Subjek penelitian ini adalah pihakpihak yang dijadikan narasumber dalam penelitian, yaitu meliputi Perempuuan yang telah bercerai atau ditinggal suami meninggal. Perempuan bekerja mencari nafkah dan berstatus single parent. Perempuan single parent yang masih menyekolahkan anaknya.

\section{Teknik Pengumpulan Data}

Teknik pengumpulan data yang digunakan adalah observasi, wawancara dan dokumentasi. Pada penelitian ini proses pengumpulan data melalui teknik observasi akan menggunakan observasi pengamat sebagai pemeran serta terhadap kegiatan yang dilaksanakan. Wawancara dilakukan kepada para narasumber yaitu, perempuuan yang telah bercerai atau ditinggal suami meninggal, perempuan bekerja mencari nafkah dan berstatus single parent, perempuan single parent yang masih 
menyekolahkan anaknya. Dokumentasi pada penelitian ini untuk menggambarkan data dari hasil analisis terhadap dokumen dokumen, arsip serta foto yang terkait dengan Pendidikan Anak dalam Keluarga Single Parent Perempuan dan lain-lain.. Dokumentasi yang didapatkan oleh peneliti akan mampu melengkapi hasil pengambilan data selama proses penelitian.

\section{Teknik Analisis Data}

Teknik analisis data yang digunakan dalam penelitian Pendidikan Anak dalam Keluarga Single Parent Perempuan ini adalah model analisis interaktif Miles and Huberman.

Aktivitas dalam analisis data, yaitu pengumpulan data, kondensasi data, penyajian data, penarikan kesimpulan (Miles and Huberman dalam Sugiyono, 2015: 246).

\section{HASIL DAN PEMBAHASAN}

\section{Pendidikan Anak dalam Keluarga Single Parent Perempuan}

a. Pendidikan Anak dalam Keluarga Single Parent Perempuan

Single parent perempuan dalam melaksanakan pendidikan keluarga menerapkan beberapa cara agar proses pendidikan dapat berjalan dengan baik dan dapat mencapai tujuan pendidikan yang ingin dicapai. Salah satu single parent perempuan memberikan pendidikan di dalam keluarga dengan cara memberikan nasihat serta dengan memberi teladan, memberikan pengawasan, serta memberikan hukuman. Memberikan nasihat merupakan cara yang sering digunakan oleh single parent perempuan dan digunakan untuk menanamkan nilainilai positif kepada anak. Single parent menanamkan nilai-nilai positif kepada anak dengan dengan memberikan contoh agar anak meniru perilaku yang dicontohkan tersebut oleh orang tua. Keteladanan memiliki pengaruh terhadap pembentukan sikap dan kepribadian seorang anak karena anak cenderung mengikuti segala sesuatu yang dilakukan oleh orang yang diseganinya termasuk orang tua seperti pendapat Hasbullah (2012) bahwa anak mengenal berbagai macam nilai dengan meneladani nilai-nilai yang melekat pada orang-orang yang disegani dan dikaguminya sehingga muncul gejala identifikasi positif dalam diri anak yang sangat penting dalam pembentukan kepribadian.

Memberikan pengawasan dan aturanaturan merupakan salah satu cara yang dilakukan oleh single parent dalam pendidikan anak dalam keluarga. Pengawasan terhadap anak dibeberapa keluarga dilakukan oleh single parent 
perempuan itu sendiri. Pengawasan bukan sekedar dilakukan untuk mengontrol kegiatan anak sehari-hari, namun juga untuk mengamati, dan memberikan perhatian terhadap kegiatan anak seharihari, agar anak mampu berkembang dan tidak terpengaruh oleh perilaku negatif dari lingkungan sekitar. Seperti single parent perempuan harus mengetahui dengan siapa anak bermain, dan anak hanya boleh bermain di wilayah yang dapat di ketahui oleh pengawasan single parent perempuan.

Memberikan hukuman merupakan cara yang dilakukan orang tua agar peraturan yang dibuat dipatuhi oleh anak. Pemberian hukuman fisik kepada anak masih dilakukan oleh single parent perempuan di desa Karangrejek Wonosari. Namun hukuman fisik tidak selalu diberikan oleh single parent perempuan setiap saat anak melakukan kesalahan, melainkan hanya ketika anak melakukan kesalahan yang dirasa berat oleh single parent perempuan. Selain itu single parent perempuan juga memberikan teguran dan peringatan agar anak tidak mengulangi kesalahannya lagi seperti halnya yang dikatakan oleh Tjipta Susana (2010) menyebutkan hukuman yang diberikan kepada anak tidak selalu berupa hukuman fisik.

Ada beberapa fungsi pendidikan keluarga yang terlihat salah satunya adalah fungsi menanamkan dasar pendidikan

moral oleh orang tua single parent perempuan kepada anak dan diajarkan pada anak. Dasar pendidikan moral didalam keluarga dilakukan oleh orang tua single parent perempuan dengan menanamkan nilai moral kepada anak. Penanaman nilai moral merupakan sesuatu yang penting diberikan kepada anak sebagai bekal untuk bergaul di masyarakat supaya anak menjadi baik dan tidak mudah terpengaruh oleh lingkungan sekitar. Kemudian pendidikan sosial didalam keluarga single parent perempuan melalui penanaman nilai kesopanan seperti tata cara bertigkah laku yang baik, dan ukuran yang baik dan buruk yang berlaku di masyarakat. Pendidikan sosial juga diberikan kepada anak melalui interaksi dan komunikasi antara orang tua dengan anak karena interaksi dan komunikasi salah satu faktor yang mempengaruhi keberhasilan pendidikan sosial. Ada fungsi pendidikan agama di dalam keluarga single parent perempuan menerapkan pendidikan agama dengan menanamkan nilai agama kepada anak seperti membiasakan anak untuk sholat, mengajarkan anak untuk mengaji.

b. Problem yang dialami Single Parent

Perubahan pola kehidupan
keluarga single parent perempuan
menduduki dua peran sekaligus dalam
berumah tangga, yaitu sebagai ibu rumah
tangga dan sebagai ayah pemimpin rumah
Perubahan pola kehidupan 
tangga sekaligus mencari nafkah untuk melanjutkan keberlangsungan kehidupan keluarga dan membiayai sekolah anaknya. Single parent perempuan memiliki dua sikap, sebagai wanita dan ibu yang harus bersikap lembut kepada anaknya, sebagai ayah yang bersikap tegas, memegang kendali aturan tata tertib, serta berperan sebagai penegak keadilan dalam kehidupa rumah tangga. Tidak mudah bagi single parent perempuan dalam menjalani kehidupannya setelah kehilangan salah satu anggota keluarga yaitu suami, karena segala sesuatu harus ditanggung sendiri. Dalam kehidupan sosial seorang single parent perempuan harus bisa beradaptasi dan berperilaku sesuai dengan keadaan sosial.

Sebagai seorang single parent perempuan memiliki kewajiban penuh dalam hal mendidik anak dan perkembangan seorang anak. Single parent perempuan merupakan sosok yang paling dekat dengan anak-anaknya untuk itu sadar akan peran pentingnya dalam pendidikan anaknya. Selain mendapatkan pendidikan formal pendidikan dalam keluarga tugas single parent perempuan sebagai orang tua satu-satunya.

Dalam menjalani menjadi single parent perempuan meneruskan perjuangan hidup untuk anak-anaknya merupakan hal yang terberat dalam kehidupannya. Walaupun seorang single parent perempuan merasa tidak kuat dengan beban ekonomi. Kondisi ekonomi keluarga single parent perempuan relatif lemah berdampak pada terbatasnya biaya pendidikan anak yang terkadang harus berhutang, karena ada biaya pendidikan sekolah salah satunya yang harus dikeluarkan oleh orang tua itu sendiri seperti halnya yang diungkapkan oleh Mulyono (2010-77) bahwa biaya pendidikan adalah menitikberatkan upaya pendistribusian benefit pendidikan dan beban yang harus ditanggung masyarakat.

Kemudian hambatan yang dirasakansingle parent dalam pendidikan anak-ananya adalah berasal dari faktor diri anak sendiri, misalnya anak menjadi malas belajar karena banyak mainnya, suka membantah kalau diberikan nasihat, seperti halnya yang diungkapkan oleh Balson (1996 : 159) bahwa ketika diasuh oleh orang tua tunggal, maka tidak menutup kemungkinan sebagian anak akan melakukan perilaku menyimpang, seperti suka membantah dan melawan orang tua, sering menggunkan kata-kata kurang sopan, nakal dan malas belajar.

c. Solusi yang dilakukan Single Parent

Seorang single parent perempuan sebagai kepala keluarga berusaha untuk menjalani hidup dengan sebaik mungkin melakukan tugas sebagai orang tua. Perubahan peran yang dilakukan single parent perempuan adalah menanamkan 
nasihat-nasihat yang berguna untuk masa depan, menjaga perkataan dan perbuatan dengan memberikan contoh yang dilakukan single parent perempuan.

Single parent perempuan dalam ekonomi tergolong cukup dan terkadang kurang tetap merasakan bahagia. Hal ini terlihat dari perasaan single parent perempuan yang hidup tanpa seorang pasangan merasa kesepian dan kebingungan mencari nafkah untuk menyambung hidup dan mendidik anak, mengurus, memberi kasih sayang, single parent perempuan tetap bersemangat, baginya kehadiran seorang anak dan keluarga didalam hidupnya menjadikan tersemangati dan terus bangkit dalam bekerja keras memenuhi kebutuhan anak dan keluarga. Harapan untuk hidup bahagia dan hidup dengan layak, dapat memenuhi kebutuhan dirinya dan keluarganya. Serta menjadi kepala keluarga yang baik dapat memberikan contoh-contoh positif kepada anaknya, karena itu dengan adanya anak dan keluarga membuat single parent perempuan bertahan untuk tetap maju meraih kebahagian. Serta single parent perempuan tetap harus menjalankan peranan dengan baik dengan didukung oleh anak-anaknya untuk dapat bersama-sama mencapai hidup harmonis dan selaras dengan perubahan peran dan status.

Single parent berusaha bagaimanapun caranya banting tulang setiap hari, sampai kalau terpaksa tidak mempunyai biaya akan menghutang demi kecukupan dalam kebutuhan sekolah anaknya. Berusaha agar kecukupan dalam segi kasih sayang saat ada dirumah bersama anaknya, mendidik anak saat dirumah, dan berusaha dalam hal pembiayaan pendidikan anak. Ada pihak lain yang membantu keuangan yaitu dari bapak atau saudaranya untuk mengurangi beban kebutuhan sehari-hari. Karena dengan pendidikan tinggi orang tua berharap agar anak bisa hidup senang, bahagia, sukses karena berpendidikan, dan mapan seperti halnya yang dikemukakan oleh Mudyahardjo (2013)pendidikan dalam arti luas terbatas yaitu pengalamanpengalaman belajar yang terprogram dalam bentuk formal, non-formal, dan atau informal yang berlangsung sepanjang hayat untuk optimalisasi perkembangan individu agar dapat memainkan peranan hidupnya dengan tepat.

\section{SIMPULAN DAN SARAN}

\section{Simpulan}

Berdasarkan rumusan masalah, hasil penelitian dan pembahasan penelitian, maka dapat diambil kesimpulan sebagai berikut:

1. Pendidikan anak dalam keluarga single parent perempuan dalam mendidik 
anak di dalam keluarga memiliki beberapa cara yaitu memberikan nasihat, memberikan teladan, memberikan pengawasan, serta memberikan hukuman.

2. Problem-problem yang dialami ibu single parent dalam pendidikan anaknya berasal dari diri anak sendiri misalnya malas belajar, anak suka membantah kalau dikasih tahu, kondisi ekonomi yang relatif lemah berdampak pada terbatasnya biaya pendidikan anak yang terkadang harus berhutang, dan kesulitan dalam kebutuhan seharihari.

3. Solusi yang dilakukan oleh ibu single parent dalam mengatasi problem pendidikan anaknya yaitu, memberikan nasihat, memberikan motivasi, mengontrol kegiatan anak, dan single parent banting tulang setiap hari untuk memenuhi kebutuhan sehari-hari, serta mencari bantuan dari pihak lain yaitu dari bapak dan bantuan dari saudaranya.

\section{Saran}

Berdasarkan penelitian yang dilakukan dengan segala kekurangan dan keterbatasan penelitian, penulis mencoba untuk memberikan saran-saran antara lain:

1. Untuk ibu single parent

Untuk para ibu single parent diharapkan memberikan motivasi yang baik kepada anak dan contoh yang baik kepada anak, maka anak akan mengerti hal yang dijalankan orang tua yang mana membesarkan dengan sendiri tanpa ayah/suami, mencari uang tidaklah mudah.

2. Untuk masyarakat keluarga ibu single parent

Dapat memberi dukungan moral maupun material, untuk mengurangi beban dari para single parent.

\section{DAFTAR PUSTAKA}

Dwi Siswoyo, dkk. (2011). Ilmu Pendidikan. Yogyakarta : UNYPress.

Bsnp (2009). Permen No 69 Tahun. Tentang Standar Biaya. Diakses pada tanggal 15 Desember 2018 dari http://bsnp-indonesia.org/id/wpcontent/uploads/2009/06/PermenNo-69-Tahun-2009-Ttg-StandarBiaya.pdf

Ollenburger. Jane C dan Moore. Helen A. 1996. Sosiologi Wanita. Jakarta : PT. Rineka Cipta.

Hasbullah. (2012). Dasar-dasar Ilmu Pendidikan. Jakarta: PT Raja Grafindo Persada

Ristekdikti. (2003). Undang-Undang 
Nomor 20 Tahun 2003 tentang

Sistem Pendidikan Nasional.

Diakses pada tanggal 2 januari 2019

dari

http://kelembagaan.ristekdikti.go.id

$\underline{w p}-$

contentuploads201608UU_no_20_t

h_2003.pdf.

Tjipta Susana. (2010). Mempertimbangkan

Hukuman Pada Anak. Yogyakarta:

Kanisius

Undang-undang Republik Indonesia Nomor

35 Tahun 2014 Tentang Perubahan

Atas Undang-Undang Nomor 23

Tahun 2002 Tentang Perlindungan

anak 